\title{
Challenge Study: A Project-Based Learning on a Wireless Communication System at Technical High School
}

\author{
IkuoTerasawa $^{1}$ \\ ${ }^{1}$ Advanced Medical Engineering, Interdisciplinary Graduate School of Medicine, Engineering and Agriculture, \\ University of Yamanashi, Japan \\ Correspondence: IkuoTerasawa, Advanced Medical Engineering, Interdisciplinary Graduate School of Medicine, \\ Engineering and Agriculture, University of Yamanashi, Takeda 4-3-11, Kofu, Yamanashi, 400-8511, Japan. Tel: \\ 81-552-350-806. E-mail: ikuo@terasawa.main.jp
}

Received: December 15, 2015

Accepted: December 28, $2015 \quad$ Online Published: January 11, 2016

doi: 10.5539/hes.v6n1p110

URL: http://dx.doi.org/10.5539/hes.v6n1p110

\begin{abstract}
The challenge study is a project based learning curriculum at Technical High School aimed at the construction ofawireless communication system. The first period was engineering issues in the construction of an artificial satellite and the second period was apositional locating system based on the general purpose wire-less device-ZigBee device. The effectiveness of the program was evaluated on the basis of participants' satisfaction and a metamorphosis in the learning and understanding of wire-less telecommunication technology.
\end{abstract}

Keywords: MICRO Satellite, wireless sensor networks, ZigBee: IEEE-802.15.4, advancedtechnical education

\section{Introduction}

Project-Based Learning (PBL) at technical high schools showsanabundance of variety. Suitable selection of engineering issues is a matter of trial-and-error technique and is a struggle at each technical high school. Daily life is an overflow of wireless terminals such as smart phones and tablet terminals. It is hard to acquire the skill in wireless telecommunication in the early stage of the curriculum for the students at electronics and electrical engineering program. Technical education of young generations is executed in three educational categories: three-year curriculum at technical high school; five-year curriculum at technical institute; and faculty of engineering at universities. Technical high school and technical institute carry the part of the education of youngest population of electronics engineers. In this work, two types of project-based learning have been realized: development of an artificial satellite and and a wireless locating system using general purpose communication device. The enhanced learning on the wireless-transmission system and integrated program of microcomputers are proposed.Significant part of students was stimulated to acquire the programming as well as the wireless communication skills, which was proved in the acquirement of official licence of telecommunication and programming.

1) Why is this problem important?

The importance of the educational program at junior high school and technical high schools are increasingly recognized, because enginnnering education at lower ages can stimulate learning of software and hardware of wireless communication and embedded microcomputer technology.

2) What are the practical implications of the study?

Students of the experienced group acquired programming sskills after the enthusiastic study on the wireless telecommunication and embetted miconputer technology. Some of students acquired professional licence in the electronics, and some part of students continued their study at university.

\section{Design of the Project-Based Learning}

In the Project-Based Learning, the aims are acquiring of the curriculum development and the academic ability of students. This is carried out in a compulsory class in the third-year curriculum, in groups of 5 to 8 students guided by one teacher. Nowadays, an abundance of digital-wireless communication has been established: smart-phones and tablet, etc., the practice of the wireless communication is rare, although it is desirable. Thus, the establishment theme is the application of the dijital wireless-communication. 


\subsection{Building an Artificial Satellite Wireless-Communication System}

The first project is the application of the building of a satellite main frame, Power Control System (PCS), and a digital wireless-communication system to the technical education for the third year students at electronics and electrical engineering class. In past ten years, artificial satellites were built and actually launched by university laboratories, such as Nakasuka Laboratory at the University of Tokyo and Matsumoto Laboratory at Tokyo Institute of Technology. The engineering issues for its construction can be projected for the present object based on what has been learned at technical high school. Figure 1 showsw the construction of the artificial satellite KAPPA-I.

High educational efficiency was demonstrated in the project based learning to build the artificial satellite, photo-voltaic panel, and a tracking antenna system. The satellite was named KAPPA-I by the students, using $\mathrm{K}$ for Kofu, which is the location, $\mathrm{K}$ for the word for technical high school, and after a legendarycreature called the kappa.
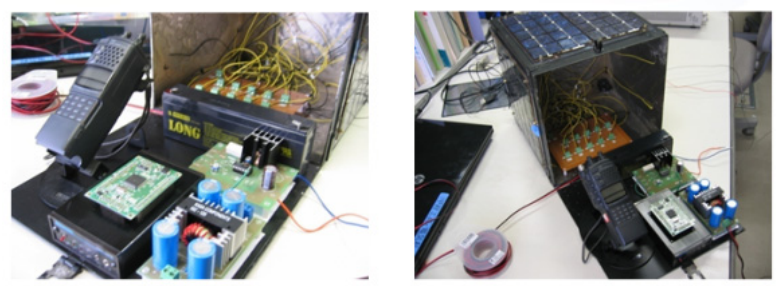

(a)

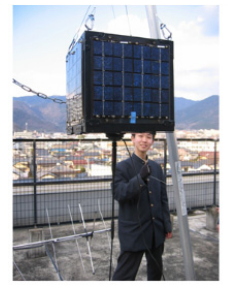

(b)

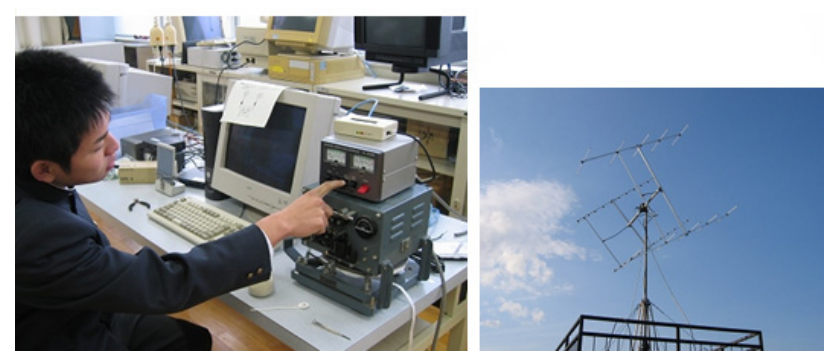

(c)

Figure 1. Building KAPPA-I. (a) building the main frame, a power control system, (b) anartificial satellite body covered with photovoltaic cells, and (c) a student engaged in the experimental setup of the ground antenna system

\subsection{Building a Wireless-Locating System Using ZigBee}

ZigBee is a communication module launched by Digi International Corp. Minnetonka, MN, USA, in 2007. Generally, the wireless communication is realized by the design of high frequency circuits. The regal conformity of the wireless transmission system is subject to investigation by the Radio Regulatory Commission and laws governing radio. Nevertheless, the wireless applicationsusingthe ZigBee are open to use without licenses. In normal conditions, the wireless transmission-range by ZigBee Type ZB is approximately 40 meters. A location system is managed by a "coordinator" just one full-function ZigBee in the system, and several transmitters, "routers". The location of and "end device" is realized by the proximity methos, finding the router transmitting the signal. This system is a simplified cellular phone system. Pushing a button on the end device, the user can transmit a signal from the end deviceandvice versa. The project based learning; wireless locating system was tested in two school rooms. Figure 2 shows some schematic diagram of the situation and a student engaged in the operating of the end device. 

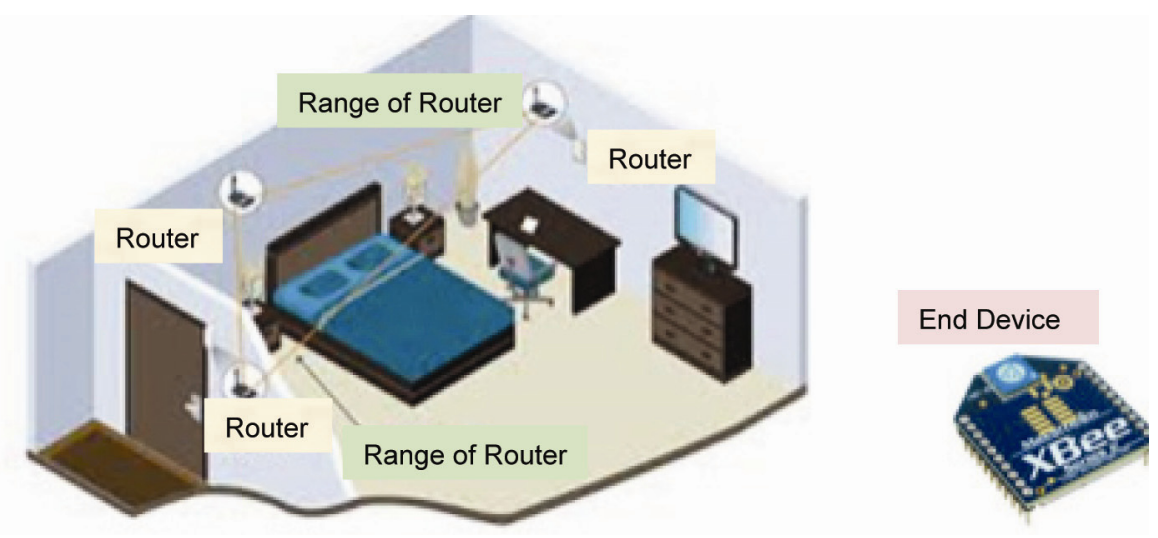

Figure 2. Project of the wireless locating system: a schematic figure showing a locating system in the interior of a building

Figure 3 (a) outlines the wireless locating system, with many routers for one end device, and (b) shows the general use of the ZigBee with one router transmitting the signal from many end devices.

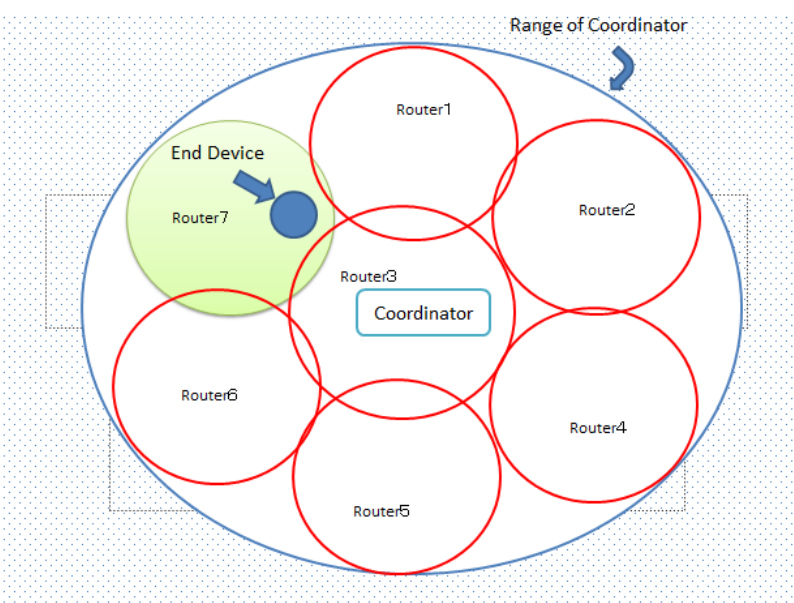

(a)

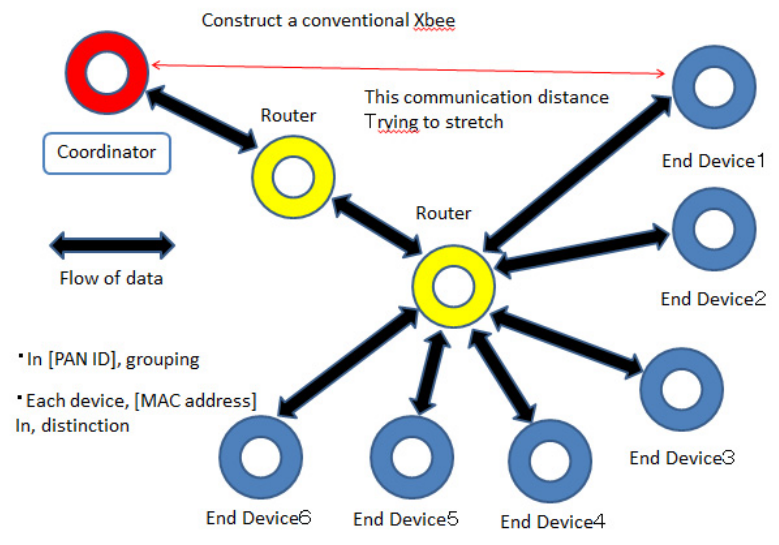

(b)

Figure 3. ZigBee units (a) the locating system: distributed routers receiving the signal from one end device and (b) general ZigBee wireless transmission sustem: one router receiving many end devices 
In this experiment, the function of ZigBee devices is classified into three categories: (1) coordinator is located at the center controls the entire network system (PAN); (2) multiple router units work in the network to control end devices and detects the ID of the end device inside the territory, and transmits the packets carrying the information about the end device along with its own ID; and (3) end devices intermittently call "pings" to the "router". Appropriate signals from the end device can be interpreted as a medical emergency calls, etc. The constructed end device is shown in Figure 4 (a). This device can be realized as a wire or chip antenna ZigBee device suitable for the wearable applications. This unit is powered by two dry cells and operated intermittently. The CPU is Arduino-Fio. The router is shown in Figure 4 (b). This router unit is powered by AC and the CPU is Arduino-UNO. The processing speed of the router should be faster than that of the end devices. Figure 4 (c) shows the coordinator, and its CPU is ARM mBed, and Figure 4 (d) shows a student engaged in the operation of the end device. Three types of ZigBee devices were used in the project, as in Table 1.

Table 1. Device types of ZigBee

\begin{tabular}{llll}
\hline \multirow{2}{*}{ Device type } & \multicolumn{2}{l}{ Playing role } & \\
\cline { 2 - 4 } & PAN & Router & Management of end device \\
\hline PAN coordinator & YES & YES & YES \\
Router/Full function End device & NO & YES & YES \\
Energy saving end device & NO & NO & NO \\
\hline
\end{tabular}

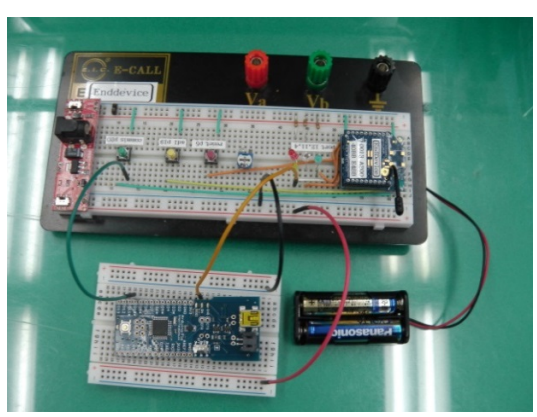

(a)

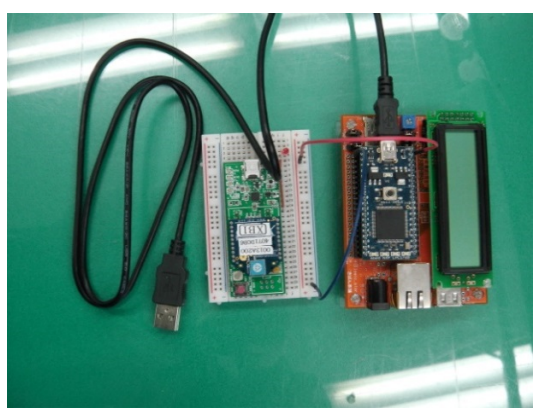

(c)

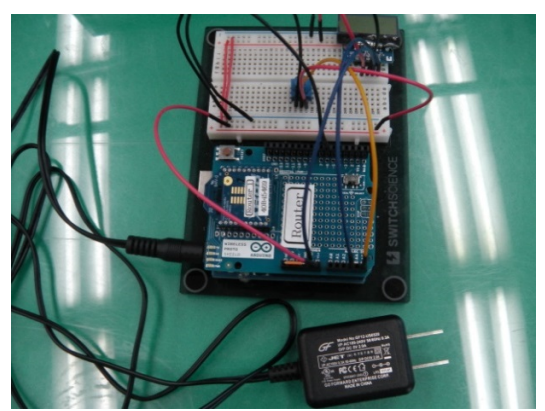

(b)

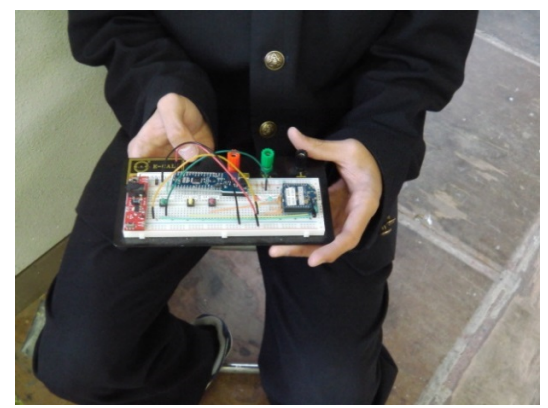

(d)

Figure 4. ZigBee units, (a) end device, (b) router, and (c) coordinator, (d) a student engaged in the operation of the end device

The recognition and signal transmission experiment were tested in three school rooms located in the neighbor hood and the experimental result are shown in Table 2. 
Table 2. Experimental result

\begin{tabular}{lll}
\hline \multirow{2}{*}{ Location } & ZigBee device's operation & \\
\cline { 2 - 3 } & ZigBee Devices & Experimental result \\
\hline Laboratory-1 & End device 1 and Router 1 & Router 1 recognized end device 1 \\
Laboratory-2 & Coordinator & Recognized router 1 and 2 \\
Laboratory-3 & End device 2 & Router 2 recognized no end device \\
\hline
\end{tabular}

Although the cross-talk between the end device and the router should be qualified, the end device was successfully localized. In the future applications, sensing devices such as the router will be embedded in the interior of a house. In the graying of Japanese society, keeping close watch of the elderly population living alone using this technology should help overcome anxiety. The end device localization and the emergency signal transmission can resolve. The programming of the micro-computers was performed by seven students, in 24 hours ( 3 hours each times 8 weeks of practical training). Arduinos were programmed by standalone mode and the mBed was programmed by a computer connected to cloud programming environment, copying library programs descriptions for the ZigBee. These results suggest that this program is suitable for the execution of the Project Based Learning at technical high schools.

\section{Conclusion}

The application of the wireless telecommunication was examined as a theme for the project based learning at technical high school. From the view point of the technical education, of young generations, such simple systemstoexperience of the wireless communication can be an effective curriculum for Project-Based Learning. The first part described the application of the digital satellite communication in technical education. The second part described the locating system using the general-purpose wireless transmission system. This study was aimed at improvement of the teaching method in the electronics and electrical engineering curriculum at a technocal high school. Presently, the project based learning at the technical high school is termed for third-year students, working in a group of 5 to 8 students, as a compulsory subject guided by one teacher. Although the execution of the wireless near field transmission is becominganindispensable theme, actually, only a few practical projectcan be found. In this study, after the construction, a sense of metamorphoses and great accomplishment was observed. In the first period, the execution was started in 2006 and continued to 2013, the enhancement of the learning skill was observed in 15 student's mark in every year and almost 500 students showed similar enthusiasm for learning. Some of the students continued their study at university. In the second period, executed in 2015, out of 35 third-year students, 7 students in the learning project were qualified as the Special Purpose Radio Operator as well as the National Skills Competition, showing the evidence of the enhancement of the learning skill and their enthusiasm to learn. Finally, the most effective period for the technical education is the junior high school and at the technical high school realized by the project based learning.

\section{Acknowledgement}

Heartfull thanks to graduated students of Kofu Technical High School, in 2006-2013, and students of Nirasaki Technical High School in 2015.

\section{References}

Fujihashi, K., Omagari, K., Fujiwara, K., Konda, Y., Maeno, M., Tanaka, Y., ... Matsunaga, S. (2008). The Institute of Electronics, Information and Communication Engineers. Techinical Report, 2008(2), 33-38.

Kinney, P. (2015). ZigBee Technology: Wireless Control that Simply Works. Resource Guide, ZigBee Alliance, 2015-1026. Davis, CA. 95616, USA.

Konda, Y., Usuda, T., Sagami, T., Omagari, K., Kashiwa, M., \& Matunaga, S. (2006). Development of Attitude Determination and Control System forPico-Satellite Cute-1.7+APD. The 16th Workshop Astrodynamics and Flight Mechanics, 2006, 242-247.

Maeno, M., Omagari, K., Iljic, T., Masumoto, S., Fujiwara, K., Konda, Y., ... Matunaga, S. (2007). Development of Tokyo Tech Nano-SateliteCute-1.7+APD II. JAXA Astrodynamics and Flight Mechanics, 2007.

Moro, T., Moriguti, H., \& Sato, T. (2005). Sensing Room-One room type everyday behavior accumulation environment second generation robotic Room. Journal of the Robotics Society of Japan, 23(6), 25-29. 
Nakasuka, S. (2000). Micro satellite and space education. J. Space Technology and Science, 16(1), 1-8.

Nakasuka, S., Sako, N., Tsuda, Y., Eishima, T., Funase, R., Nakamura, Y., \& Nagai, M. (2005). University of Tokyo's CubeSat-XI and Approach to Low Cost and Quick Space Development Using Micro/Nano Satellites. The Institute of Electronics, Information and Communication Engineers, J88-B(1), 41-48.

Omagari, K., Miyashita, N., \& Matsunaga, S. (2006). Development, Launch and Operationof Tokyo Tech's Nanosatellite Cute-1.7+APD. The 16th Workshop on JAXA Astrodynamics and Flight Mechanics, 2006(1-2), 209-214.

Qualification, Secondary land special radio engineer. (n.d.). Japan Radio Association. Retrieved from http://www.nichimu.or.jp/

Standard, ZigBee Alliance. (n.d.). 508 Davis, CA, 95616, USA. Retrieved from http://www.zigbee.org/

Terasawa, I. (1999). A Study on multimedia method and technology education (master's thesis). Yamanashi University (Former), Kofu, Yamanashi, Japan.

Terasawa, I. (2007). Space Station Amateur Communication Technology: Utilization to Technical Education. Japan Society of Technology Education, the 50th National Convention. Osaka Kyoiku University, Osaka, Japan.

Terasawa, I. (2010). Development of Ultra-small Satellite Kappa-I. Japan Society of Technology Education, Information Subcommittee the 25th. Fukuoka University, Fukuoka, Japan.

Tsuda, Y., Sako, N., Eishima, T., Ito, T., Arikawa, Y., Miyamura, N., ... Nakasuka, S. (2001). University of Tokyo's CubeSat project-Its educational and technological significance. The 15th Annual AIAA/USU Conference on Small Satellites, Utah.

Tsuda, Y., Sako, T., Eishima, N., Ito, T., Arikawa, Y., Miyamura, N., ... Nakasuka, S. (2000). University of Tokyo's CubeSat project-Mission concept and subsystem design. J. Space Technology and Science, 16(1), 37-46.

\section{Copyrights}

Copyright for this article is retained by the author(s), with first publication rights granted to the journal.

This is an open-access article distributed under the terms and conditions of the Creative Commons Attribution license (http://creativecommons.org/licenses/by/3.0/). 